\title{
Antibiogram of Escherichia coli and Staphylococcus aureus Isolated from Milk Sold in Kathmandu District
}

\author{
Shyamala Rai, Barsha Karki, Sujita Humagain, Sandesh Rimal, Sandhya Adhikari, Shilpa Adhikari, \\ Suchitra Thapa $\bigcirc$ \\ Amrit Campus, Tribhuvan University, Department of Microbiology, Thamel, Kathmandu \\ Article history:- Received: 15 Jun 2020; Revised: 17 Dec 2020; Accepted: 18 Dec 2020; Published online: 30 Dec 2020
}

\begin{abstract}
The emergence of antibiotic resistance in microorganisms and the presence of such isolates in milk pose a great risk to public health. Therefore, this study aims to determine the antibiotic susceptibility pattern of Escherichia coli and Staphylococcus aureus isolated from milk and assess the microbial quality of milk. For this, a total of 70 milk samples were collected and the total bacterial count (TBC) was determined. E. coli and S. aureus were isolated using their respective selective media while antibiotic susceptibility testing was carried out by Kirby Bauer Disc Diffusion method. The TBC showed that the raw milk samples contained two-fold higher microbial load while the pasteurized milk samples contained four-fold higher microbial loads than the standard guidelines. A total of 62 isolates were identified from culture-positive milk samples of which 32 were $E$. coli and 30 were S. aureus. A significant correlation was observed between microbial load and the organism isolated $(r=0.339, p<0.01)$. All S. aureus isolates were susceptible to Chloramphenicol while $40 \%$ were resistant to Cefoxitin, indicating the presence of Methicillin resistant $S$. aureus (MRSA). Also, 12 multidrug resistant (MDR) S. aureus were identified. While for $E$. coli, all were susceptible to Chloramphenicol but resistant to Ampicillin. Also, 9 MDR E. coli were detected. Higher resistance was observed among isolates from the raw milk samples than the pasteurized milk. It can be concluded that the milk produced by smallscale farms and dairy industries of Kathmandu district are of poor quality. Hence, routine microbial quality assessment and antimicrobial resistance monitoring should be followed to safeguard public health.
\end{abstract}

Keywords: Antibiotic resistance, Milk-borne infection, Multidrug resistance, E. coli, S. aureus, Total bacterial count, MRSA

Corresponding author, email: suchitrathapa69@gmail.com

\section{Introduction}

Milk, a daily diet requirement of people, can become microbiologically hazardous to consumers when the principles of hygiene and sanitation are not met. Such conditions may become a vehicle for transmission of food-borne infections [1]. Among all microorganism, Escherichia coli and Staphylococcus aureus are the most common food contaminants [1]; and in recent years, both are observed to cause a number of significant illnesses in animals and humans [2]. S. aureus is specifically a versatile pathogen capable of causing numerous diseases in humans [2]. In addition, it is also a major causative pathogen of clinical or subclinical mastitis of dairy animals [1]. Further, MRSA together with Extended Spectrum $\beta$-Lactamase (ESBL) producing E. coli, are considered as serious threats to human health [3]. Therefore, the relative importance of these pathogens along with other pathogenic microorganisms in milk is inevitable. But the lack of awareness about milk-borne infections in many developing countries and consumption of contaminated milk predisposes consumers at risk of contracting infections with these pathogens [4].
Antibiotics are essential to treat infections caused by pathogenic bacteria, both in humans and animals. However, their overuse and misuse in veterinary and human medicine has been linked to the emergence and spread of resistant bacteria, rendering the treatment of infectious diseases ineffective in animals and humans. And, now antimicrobial resistance is one of the main threats to modern medicine [5]. Further, the escalating prevalence of antimicrobial resistance among foodborne pathogens $[6,7]$ has exaggerated the public health hazards including milk-borne infections. Available studies around the world have reported about the presence of multidrug resistant E. coli [8], ESBL [9, 10], toxin-producing S. aureus [11] along with MRSA strains $[7,11]$ in milk samples but in the case of Nepal very less studies are found on antibiotic resistance of milk isolates. Therefore, it is necessary to know the microbial quality of marketed milk and understand the recent trend of antimicrobial resistance among milk pathogens so as to properly diagnose and treat the infection. This study was conducted to determine the current trend of antibiotic resistance of E. coli and S. aureus isolated from milk and assess the microbial quality of milk sold in Kathmandu district. 


\section{Materials and Methods}

\section{Sampling site and sample}

A total of 70 milk samples were tested in this study. Forty raw milk samples (30 $\mathrm{ml}$ each) from 4 different municipalities of Kathmandu district (KageshworiManohara, Chandragiri, Tarkeshwor and Dakshinkali Municipality) were collected in a sterile screw capped bottle and transported to laboratory in an icebox within 2 hours. Further, 30 pasteurized milk pack $(500 \mathrm{ml})$ was bought from local vendors from the same municipalities. The collection of the sample was done from December 2018 to March 2019 in compliance with the guidelines stated in Bacteriological Analytical Manual [12].

\section{Total bacterial count of milk samples}

The collected milk samples were serially diluted up to $10^{-8}$ dilution. The bacterial count was determined by culturing the serially diluted milk samples. Conventional pour plate technique was employed for culturing the diluted milk samples [13].

\section{Isolation and identification of $E$. coli and $S$. aureus}

Isolation of E. coli and S. aureus was done by enrichment in buffered peptone water and cultured in EMB (Eosin Methylene Blue) and MSA (Mannitol Salt Agar) media respectively [14]. The distinct colonies were identified and confirmed by following their respective biochemical characteristics [13].

\section{Antibiotic susceptibility testing of milk isolates}

Isolates of E. coli and S. aureus were subjected to antibiotic susceptibility testing using Kirby Bauer disk diffusion method as recommended by CLSI [15]. The antibiotics used for E. coli were Ampicillin $(10 \mu \mathrm{g})$, Chloramphenicol $(30 \mu \mathrm{g})$, Ciprofloxacin $(5 \mu \mathrm{g}), \quad$ Nalidixic acid $(30 \mu \mathrm{g})$, Tetracycline $(30 \mu \mathrm{g})$ and Ceftriaxone $(5 \mu \mathrm{g})$; and for $S$.

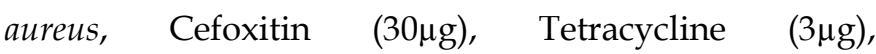

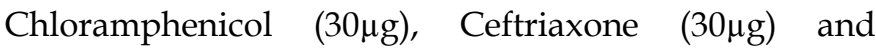
Ciprofloxacin $(5 \mu \mathrm{g})$ were used.

\section{Data analysis}

The data was initially entered in MS Excel and exported to SPSS. The frequency distribution, normal distribution testing, variance analysis and correlation were done using SPSS (version 20). The significance was measured at both $95 \%$ and $99 \%$ confidence interval. The resistance profile was analyzed using WHONET2019 (32-bit version 19.13.21) and the outcome was interpreted accordingly.

\section{Results \\ Microbial load of milk samples}

The TBC of raw milk ranged from $0.31 \times 10^{5} \mathrm{CFU} / \mathrm{ml}$ to $1000 \times 10^{5} \mathrm{CFU} / \mathrm{ml}$ with mean TBC of $8.13 \times 10^{6} \mathrm{CFU} / \mathrm{ml}$ $\left(\mathrm{S} . \mathrm{D}=18.9 \times 10^{6}\right)$. Likewise, the TBC of pasteurized milk ranged from $0.35 \times 10^{3} \mathrm{CFU} / \mathrm{ml}$ to $1600 \times 10^{3} \mathrm{CFU} / \mathrm{ml}$ with mean TBC of $14.25 \times 10^{4} \mathrm{CFU} / \mathrm{ml}\left(\mathrm{S} . \mathrm{D}=29.71 \times 10^{4}\right)$.

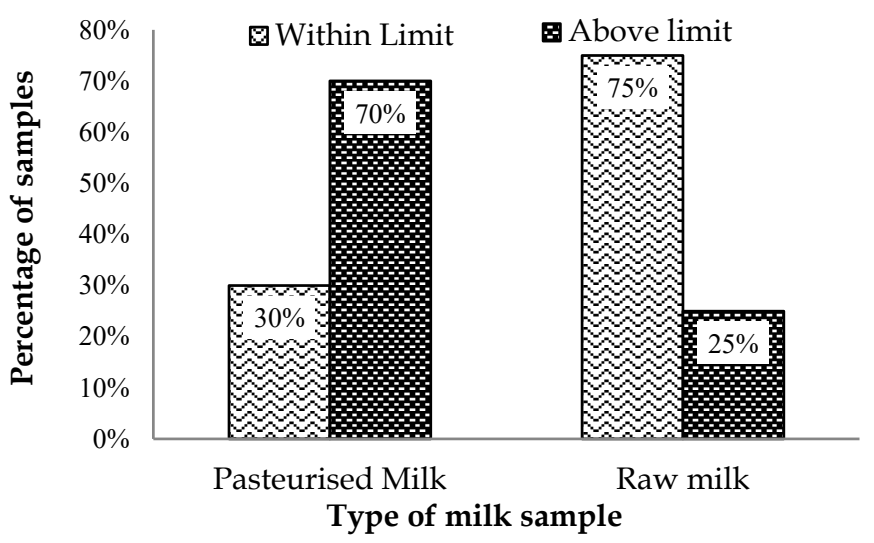

Figure 1. Quality of milk samples according to BIS standard guideline.

For raw milk, the TBC exceeding $50 \times 10^{5} \mathrm{CFU} / \mathrm{ml}$ is graded as poor while below it is graded either fair, good and very good according to Bureau of Indian Standards (BIS) [16] and are considered within safe limit. Following this Standard, among the total raw milk samples 14 samples were observed to fall under "very good" grading, 6 under "good" grading, 10 under "fair" grading and rest 10 under "poor" grading. In case of pasteurized milk, 9 samples had TBC below $3 \times 10^{4} \mathrm{CFU} / \mathrm{ml}$ and 21 samples had higher than that. The distribution of milk samples in terms of their standard limit of TBC is given in Figure 1. Statistically, a highly significant difference was observed in the distribution of TBC across the raw and pasteurized milk sample $(\mathrm{p}<0.01)$.

\section{Prevalence of $E$. coli and $S$. aureus in Milk}

$E$. coli and S. aureus were isolated from raw and pasteurized milk samples using selective media (Figure 3A and 3B). Out of 70 samples, 46 (65.71\%) samples showed culture positivity towards E. coli or S. aureus or to both. The percentage distribution of organisms among the raw and pasteurized milk sample is given in Figure 2. It was observed that the distribution of microbial count is not the same across culture positivity $(p<0.05)$ and isolated organism $(\mathrm{p}<0.01)$.

A total of $32 \mathrm{E}$. coli isolates were subjected to antibiotic susceptibility test using Ciprofloxacin, Ceftriaxone, Chloramphenicol, Nalidixic acid and Ampicillin antibiotic disc. 
Table 1 Antibiotic resistance profile of E. coli $(\mathrm{n}=4)$

\begin{tabular}{|c|c|c|c|c|c|}
\hline Milk sample type & Resistance antibiotics & Number of E. coli & Importance Resistance & Priority & Inference \\
\hline Raw milk & AMPR NARCTRR & 1 & Yes* $^{*}$ & Medium* & Possible ESBL \\
\hline Pasteurized milk & AMPR TER NAR TTRR $^{R}$ & 2 & Yes* & Medium* & Possible ESBL \\
\hline Raw milk & AMPR TER CIPRCTRR & 1 & Yes $^{*}$ & Medium $^{*}$ & Possible ESBL \\
\hline
\end{tabular}

* According to the WHONET 2020 software interpretation

Legends: AMP-Ampicillin, NA-Nalidixic acid, CTR- Ceftriaxone, TE-Tetracycline, CIP-Ciprofloxacin

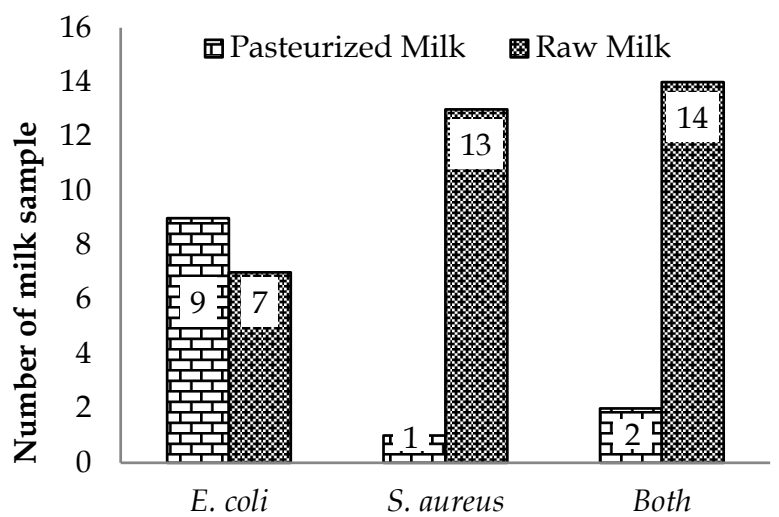

Organism Isolated from milk samples

Figure 2. Distribution of E. coli and S. aureus in the milk sample $(\mathrm{n}=46)$

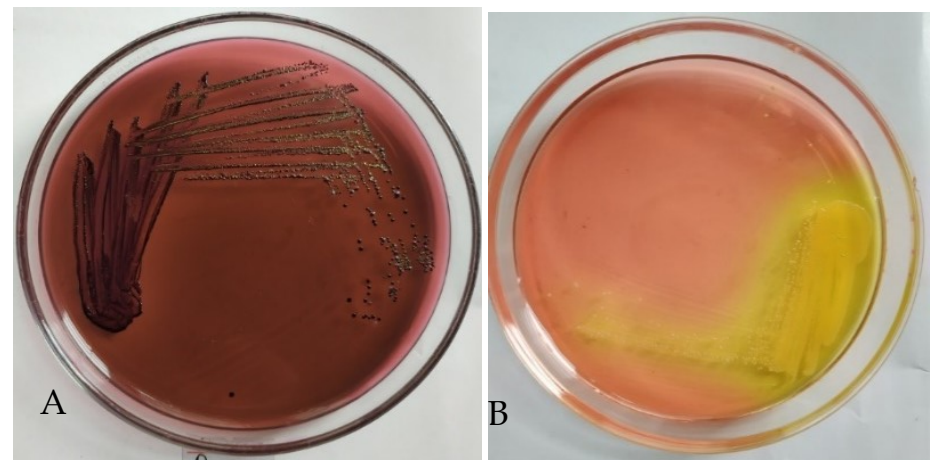

Figure 3A: E. coli Culture on EMB media plate and 3B: $S$. aureus culture on MSA media plate

\section{Antibiogram of $E$. coli}

All the isolates showed $100 \%$ susceptibility towards Chloramphenicol while none of the isolates showed susceptibility towards Ampicillin. Also, the susceptibility for Ciprofloxacin, Ceftriaxone, Tetracycline and Nalidixic acid were $96.88 \%, 87.5 \%, 81.25 \%$ and $78.13 \%$, respectively. Of the $9 \mathrm{MDR} E$. coli identified, 4 isolates of important antibiotic resistance was recognized through antibiogram analysis. A detail resistance profile of these isolates is provided in Table $\mathbf{1}$.

\section{Antibiogram of $S$. aureus}

A total of $30 \mathrm{~S}$. aureus isolates were subjected to antibiotic susceptibility test using Cefoxitin, Ciprofloxacin, Ceftriaxone, Chloramphenicol and Nalidixic acid antibiotic disc. All the isolates showed 100\% susceptibility towards Chloramphenicol, while the susceptibility for Tetracycline, Ciprofloxacin, Cefoxitin and Ceftriaxone were $93.33 \%, 70 \%, 60 \%$ and $30 \%$, respectively. A total of $12 \mathrm{MDR}$ S. aureus (40\%) were identified and they were confirmed as MRSA due to their resistance towards Cefoxitin. A detail resistance profile of important isolates of $S$. aureus is provided in Table 2 .

Table 2 Antibiotic resistance profile of $S$. aureus $(\mathrm{n}=12)$

\begin{tabular}{|c|c|c|c|c|}
\hline $\begin{array}{c}\text { Milk sample } \\
\text { type }\end{array}$ & $\begin{array}{l}\text { Resistance } \\
\text { antibiotics }\end{array}$ & $\begin{array}{l}\text { No of } \\
\text { S. aureus }\end{array}$ & $\begin{array}{l}\text { Importance } \\
\text { Resistance }\end{array}$ & Priority \\
\hline Raw milk & CIPR CXR & 2 & Yes $^{*}$ & Medium* \\
\hline Raw milk & $\mathrm{CTR}^{\mathrm{R}} \mathrm{CX}^{\mathrm{R}}$ & 6 & Yes $^{*}$ & Medium ${ }^{*}$ \\
\hline Raw milk & $\begin{array}{l}\mathrm{CTR}^{\mathrm{R}} \mathrm{CX}^{\mathrm{R}} \\
\mathrm{TE}^{\mathrm{R}}\end{array}$ & 1 & Yes $^{*}$ & Medium* \\
\hline Raw milk & $\begin{array}{l}\text { CTRR }^{R} \text { CX R } \\
\text { CIPR }\end{array}$ & 1 & Yes* $^{*}$ & Medium* \\
\hline $\begin{array}{l}\text { Pasteurized } \\
\text { milk }\end{array}$ & $\begin{array}{l}\text { CTRR }^{R} C^{R} \\
\text { CIPR }^{R}\end{array}$ & 2 & Yes $^{*}$ & Medium $^{*}$ \\
\hline
\end{tabular}

${ }^{*}$ According to the WHONET 2020 software interpretation Legends: CX-Cefoxitin, CTR- Ceftriaxone, TE-Tetracycline, CIP-Ciprofloxacin

\section{Discussion}

This study, which examined milk samples from four different municipality of Kathmandu districts, showed high significance $(p<0.01)$ in the distribution of microbial load among the raw and pasteurized milk samples. This significance may comply with the fact that pasteurized milks are heat treated and ought to have lower microbial load. However, the majority of pasteurized milk samples (70\%) were below the standard recommended guidelines of Indian standards [16] compared to raw milk (25\%) (Figure 1). Also, the raw milk samples showed two-fold higher microbial load than the recommended value of BIS while pasteurized milk showed four-fold higher microbial load than the standard recommended value of BIS. This indicates that the pasteurized milk samples in our study were of bad quality. Such results of high microbial load may be due to inefficient pasteurization, poor packaging material and pipeline, post pasteurization contaminants, presence of heat resistant bacteria, poor air and storage condition, etc. However, as both harmful and beneficial microbes can reside in milk and higher microbial load does not necessarily indicate the exact type of microbes present in the milk, it may not be appropriate to gauge the quality of milk solely based on microbial load unless each of the microbial strain in the milk are identified. The quality issue aside, apparently similar prevalence of higher microbial load in pasteurized milk in Kathmandu was documented in a 
study conducted by Acharya et al. (2017) [17]. Even the DFTQC, Nepal reported the higher rate of noncompliance among milk and milk product in the annual bulletin of 2019 [18]. The presence of microbes in high number in treated milk sample is a risk to the consumers as the microbes present may be pathogenic strains.

In this study, almost half of the milk sample showed the presence of E. coli $(45.71 \%)$ and similar results were reported in other studies $[8,19]$. Also, a study conducted by Arjyal et al. (2004), has reported E. coli prevalence rate as high as $92 \%$ [20]. Understandably, E. coli is a commensal enteric microorganism; yet, as their pathogenic strains are associated with a range of illness in animal and humans especially the toxin producers (Shiga toxin-producing E.coli) and thus their presence in milk should not be overlooked. In case of S.aureus, their presence in milk is of greater concern as they also produce heat-stable toxin which causes food poisoning [1]. The finding in this study related to $S$. aureus - almost half of the milk sample $(42.86 \%)$ had the presence of $S$. aureus -is comparable to the results of several studies conducted in Nepal $[20,21]$ as well as in the rest of the world [22, 23, 24]. Statistically, a significant positive correlation $(\mathrm{p}<0.05)$ was observed in the distribution pattern of TBC across the culture; it signifies that the microbial load affects the presence of $E$. coli or $S$. aureus and vice versa. Similar correlation but with higher significance $(p<0.01)$ was observed among microbial load and the type of organism which suggests that the microbial load affects the type of organism present in the sample and vice versa. This justifies the existence of higher prevalence of S. aureus (90\%) and E. coli $(65.63 \%)$ in raw milk as they have higher microbial load (Figure 2). Regarding the antibiotic susceptibility test of E. coli and $S$. aureus, the result showed an emerging antibiotic resistance among both isolates. All the E. coli isolates in this study were resistant to Ampicillin which was in compliance with the findings of Badri et al. (2017) [9] and Singh et al. (2018) [25]. Besides ampicillin resistance, the results revealed higher resistance among $E$. coli towards Nalidixic acid, Tetracycline, Ceftriaxone and Ciprofloxacin in descending order. Even though XDR was not detected, 9 MDR was present and their antibiogram analysis indicated that 4 out of 9 isolates were important resistance of medium priority (Table 1). Such presence of MDR in milk samples were also reported in similar studies [8, 10]. This presence of MDR is of greater concern to public health and indicates an alarming situation.

While in case of $S$. aureus, the resistance was higher for most of the antibiotics except for Chloramphenicol. Such full susceptibility was also reported in various other studies of milk samples [22, 17]. Besides Chloramphenicol susceptibility, the results revealed higher resistance among $S$. aureus towards Ceftriaxone, Cefoxitin, Ciprofloxacin and Tetracycline in descending order. Further, 12 MDR (40\%) were detected which were MRSA as well, and their antibiogram analysis indicated that these are important resistance of medium priority (Table 2). Several other studies have also reported the higher prevalence of $\operatorname{MDR}[7,11,26]$ and MRSA $[7,11$, 17]. Simultaneous presence of MDR in MRSA reported in this study also resembled the study of Aliyu et al. (2020) [27]. This result indicates an emerging trend of antimicrobial resistance among $S$. aureus.

This emerging antibiotic resistance among both E. coli and $S$. aureus isolates was observed in higher number in raw milk sample compared to pasteurized milk sample. Also, the multidrug resistant isolate was found to be higher in raw milk than pasteurized milk. Since the exposure to environment is more in raw milk compared to pasteurized milk, the chances of resistant isolates finding its way to raw milk is more likely. Further the extensive misuse of antibiotics for the treatment of farm animals may have created selective pressure and resulted in the survival and persistence of resistant isolates. This emerging resistance may lead to treatment failure of the last resort drug. Thus, routine monitoring of resistant profile of milk pathogens should be implemented in order to properly diagnose and treat milk-borne infections effectively, along with the assessment of microbial quality of milk with the purpose of safeguarding the public health.

\section{Conclusion}

To conclude, the resistance towards common antimicrobials is emerging among milk isolates and infections by these isolates pose a serious threat to animal and public health. Therefore, regular monitoring programs, good farming practice training, improved standard guidelines, antibiotic surveillance program on food isolates and rational use of antibiotics are needed to improve sustainable food production and avoid the emergence of antibiotic-resistant strains.

\section{Authors' Contribution}

The development of concept, preliminary work and laboratory analysis, was done by SR, BK, SH, SR and SaA under the guidance of SuT and ShA. Further, SuT performed data analysis, prepared, reviewed and edited the manuscript. All authors read and approved the final manuscript. 


\section{Competing Interests}

The authors declare that they have no conflicts of interest.

\section{Funding}

This study was not funded by any agency or institution.

\section{Acknowledgments}

All authors are grateful to the faculty and laboratory staff of Microbiology department of Amrit Campus for their continuous support in this research work, and extent especial mention to the farm owners of Kathmandu district who supported us by providing the milk sample.

\section{Ethical Approval and Consent}

A brief detail of this research study was provided to the farm owner, and a verbal consent was obtained before sampling. This study was carried out with the approval from the concerned authorities.

\section{Data Availability}

The data can be made available upon request.

\section{References}

1. Tamime AY, editor. Milk processing and quality management. John Wiley \& Sons; 2009 Jan 30. http://www.foodtechnologist.yolasite.com/resources/Milk\%20P rocessing $\% 20$ and $\% 20$ Quality $\% 20$ Management.pdf

2. Food and Drug Administration. The Bad Bug Book: Foodborne Pathogenic Microorganisms and Natural Toxins Handbook, 2nd edn. 2012. https://www.fda.gov/downloads/Food/ FoodborneIllnessContaminants/UCM297627.pdf

3. Centres for Disease Control and Prevention (US). Antibiotic resistance threats in the United States, 2019. Centres for Disease Control and Prevention, US Department of Health and Human Services; 2019. http://www.cdc.gov/drugresistance/threatreport-2019.

4. Mosalagae D, Pfukenyi DM, Matope G. Milk producers' awareness of milk-borne zoonoses in selected smallholder and commercial dairy farms of Zimbabwe. Tropical animal health and production. 2011 Mar 1;43(3):733-9. https:/ / doi.org/10.1007/s11250-010-9761-5

5. World Health Organization. Antimicrobial resistance: global report on surveillance. World Health Organization;2014. https://apps.who.int/iris/bitstream/handle/10665/112642/9789 241564748eng.pdf

6. Threlfall EJ, Ward LR, Frost JA, Willshaw GA. The emergence and spread of antibiotic resistance in food-borne bacteria. International journal of food microbiology. 2000 Dec 5;62(1-2):1-5. https://doi.org/10.1016/S0168-1605(00)00351-2

7. Joshi LR, Tiwari A, Devkota SP, Khatiwada S, Paudyal S, Pande KR. Prevalence of methicillin-resistant Staphylococcus aureus (MRSA) in dairy farms of Pokhara, Nepal. International Journal of Veterinary Science. 2014;3(2):87-90. http://www.ijvets.com/pdffiles/Volume-3-no-2-2014/87-90.pdf

8. Rasheed MU, Thajuddin N, Ahamed P, Teklemariam Z, Jamil K. Antimicrobial drug resistance in strains of Escherichia coli isolated from food sources. Revista do Instituto de Medicina Tropical de São Paulo. $2014 \quad$ Aug;56(4):341-6. https://10.1590/s003646652014000400012

9. Badri AM, Ibrahim IT, Mohamed SG, Garbi MI, Kabbashi AS, Arbab MH. Prevalence of extended-spectrum beta-lactamase (ESBL) producing Escherichia coli and Klebsiella pneumoniae isolated from raw milk samples in Al Jazirah State, Sudan. Mol. Biol. 2017;7(1):201.https://10.4172/2168-9547.1000201

10. Batabyal K, Banerjee A, Pal S, Dey S, Joardar SN, Samanta I, Isore DP, Singh AD. Detection, characterization, and antibiogram of extended-spectrum beta-lactamase Escherichia coli isolated from bovine milk samples in West Bengal, India. Veterinary World. 2018 Nov;11(10):1423. https://10.14202/vetworld.2018.1423-1427

11. Riva A, Borghi E, Cirasola D, Colmegna S, Borgo F, Amato E, PONTELLO M, Morace G. Methicillin-resistant Staphylococcus aureus in raw milk: prevalence, SCCmec typing, enterotoxin characterization, and antimicrobial resistance patterns. Journal of food protection. 2015 Jun 1;78(6):1142-6. https:/ / doi.org/10.4315/0362-028X.JFP-14-531

12. Andrews WH, Hammack TS. BAM: Food sampling/preparation of sample homogenate. Retrieved July. 2003 Apr;19:2016. https://www.fda.gov/food/laboratory-methods-food/bamchapter-1-food-samplingpreparation-sample-homogenate

13. Cheesbrough M. District laboratory practice in tropical countries, part 2. Cambridge university press; 2006 Mar 2.

14. Singh P, Prakash A. Isolation of Escherichia coli, Staphylococcus aureus and Listeria monocytogenes from milk products sold under market conditions at Agra region. Acta agriculturae Slovenica. 2008 Nov;92(1):83-8. http:/ / aas.bf.uni-lj.si

15. Clinical and Laboratory Standards Institute. Performance standards for antimicrobial susceptibility testing. CLSI supplement M100. 2013

16. BIS DW. 10500: 1991. First Revision, Bureau of Indian Standards, India. 1992.

17. Acharya S, Bimali NK, Shrestha S, Lekhak B. Bacterial Analysis of Different Types of Milk (Pasteurized, Unpasteurized and Raw Milk) Consumed in Kathmandu Valley. Tribhuvan University Journal of Microbiology. 2017;4:32-8. https://doi.org/10.3126/tujm.v4i0.21674

18. DFTQC . Annual Bulletin. Department of Food Technology and Quality Control, Babar Mahal, Kathmandu, Nepal,8-9. 2019 http://www.dftqc.gov.np/downloadfile/DFTQC_English_Annu al_Buletin_Book_1591495040.pdf

19. Parajuli A, Rimal P, Maharjan R, Chaudhary R, Chaturwedi SB. Quality Analysis of Milk in Kathmandu Valley. Tribhuvan University Journal of Microbiology. 2018 Sep 26;5:7-10. https:// doi.org/10.3126/tujm.v5i0.22295

20. Arjyal C, Dahal BN, Khadka B. Microbial quality of milk available in Kathmandu valley. Journal of the Nepal Medical Association. 2004 May 1;43(153).https://doi.org/10.31729/jnma.475

21. Shrestha S, Bindari YR. Prevalence of sub-clinical mastitis among dairy cattle in Bhaktapur District, Nepal. International Journal of Agriculture and Biosciences. 2012;1(1):16-9. http:/ / www.ijagbio.com/wp-content/uploads/pdf-files/ Volume- 1-Issue-1-2012/16-19.pdf

22. Uddin MA, Motazzim-ul-Haque HM, Noor R. Isolation and identification of pathogenic Escherichia coli, Klebsiella spp. and Staphylococcus spp. in raw milk samples collected from different areas of Dhaka City, Bangladesh. Stamford Journal of Microbiology.

https://doi.org/10.3329/sjm.v1i1.9098

2011;1(1):19-23.

23. Titouche Y, Hakem A, Salmi D, Yabrir B, Chenouf N, Chergui A, Chenouf A, Houali K. Assessment of microbiological quality of raw milk produced at Tizi Ouzou area (Algeria). https:/ /10.3923/ajava.2016.854.860

24. Bano S, Hayat M, Samreen T, Asif M, Habiba U, Uzair B. Detection of Pathogenic Bacteria Staphylococcus aureus and Salmonella sp. from Raw Milk Samples of Different Cities of Pakistan. Natural Science. 2020; 12, 295-306. https:// doi.org/10.4236/ns.2020.125026

25. Singh A, Chhabra D, Sikrodia R, Shukla S, Sharda R, Audarya S. Isolation of E. coli from Bovine Mastitis and their Antibiotic Sensitivity Pattern. International Journal of Current Microbiology and Applied Sciences. 2018; 7(10): 11-18 https://doi.org/10.20546/ijcmas.2018.710.002

26. Massawe HF, Mdegela RH, Kurwijila LR. Antibiotic resistance of Staphylococcus aureus isolates from milk produced by smallholder dairy farmers in Mbeya Region, Tanzania. Int. J. One Health. 2019;5:31-7. https://doi:10.14202/ijoh.2019.31-37

27. Aliyu Y, Abdullahi IO, Whong CZ, Olalekan BO, Reuben RC. Occurrence and antibiotic susceptibility of methicillin-resistant Staphylococcus aureus in fresh milk and milk products in Nasarawa State, North-Central Nigeria. Journal of Microbiology and Antimicrobials. $\quad 2020 \quad$ Jan 31;12(1):32-41. https://doi.org/10.5897/JMA2020.0424 